\title{
PENERAPAN MODEL DISCOVERY LEARNING DENGAN TEKNIK PROBING PROMPTING TERHADAP KEMAMPUAN KOGNITIF PESERTA DIDIK
}

\author{
Syarifa Alam Al-Hadid ${ }^{1, a}$, Nur Aisyah Humairah ${ }^{2, b}$, Dewi Sartika ${ }^{3, c}$ \\ 1,2,3 Universitas Sulawesi Barat

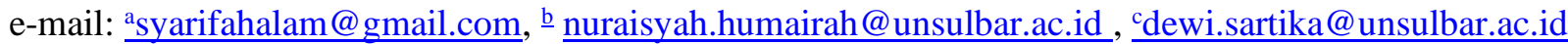

\begin{abstract}
Abstrak
Penelitian ini adalah untuk mengetahui (1) hasil kemampuan kognitif sebelum diterapkan model discovery learning dengan teknik probing prompting dalam pembelajaran fisika, (2) hasil kemampuan kognitif setelah diterapkan model discovery learning dengan teknik probing prompting dalam pembelajaran fisika, (3) perbedaan yang signifikan hasil kemampuan kognitif sebelum dan setelah diterapkan model discovery learning dengan teknik probingprompting dalam pembelajaran fisika. Jenis penelitian yang digunakan adalah penelitian pre-eksperimen desain one- group-pretest-posttest. Populasi dalam penelitian ini adalah seluruh peserta didik kelas XI SMA Negeri 1 Pamboang. Sampel penelitian diambil dengan teknik sampling purposive, sebanyak 20 peserta didik. Teknik pengumpulan data menggunakan tes pilihan ganda. Teknik analisis data menggunakan analisis deskriptif dan inferensial. Hasil penelitian menunjukkan bahwa skor rata-rata pretest sebesar 4,7 dan skor rata-rata posttest sebesar 10,6. Dengan demikian dapat diketahui bahwa (1) hasil kemampuan kognitif peserta didik sebelum diajar dengan diterapkan model discovery learning dengan teknik probing prompting berada pada kategori kurang, (2) hasil kemampuan kognitif peserta didik setelah diajar dengan diterapkan model discovery learning dengan teknik probing prompting berada pada kategori kurang (3) terdapat perbedaan signifikan antara hasil kemampuan kognitif sebelum dan setelah diterapkan model discovery learning dengan teknik probing prompting dalam pembelajaran fisika.
\end{abstract}

Kata Kunci: Penelitian Pre-eksperimen, Penerapan model discovery learning, Teknik probing prompting, Hasil kemampuan kognitif

\section{APPLICATION OF THE DISCOVERY LEARNING MODEL WITH PROBING PROMPTING TECHNIQUE TO THE COGNITIVE ABILITY OF STUDENTS}

\begin{abstract}
The research was aimed to investigate (1) The result of cognitive ability before application discovery learning model with probing prompting technique in physics learning, (2) Result of cognitive ability after application discovery learning model with probing prompting technique in physics learning, (3) The significant difference after application discovery learning model with probing prompting technique in physics learning. The type of research was used pre-experiment research with one-group-pretest-posttest design. The population in this study was all eleventh grade students of SMA Negeri 1 Pamboang. The sample was taken by purposive sampling technique, as many as 20 students. Data collection techniques used multiple choice tests. Data analysis techniques used descriptive and inferential analysis. The results showed that the average pretest score was 4.7 and the posttest average score of 10.6. Thus, it could be seen that (1) The result of cognitive ability of the learner before being taught by application the discovery learning model with probing prompting technique is in the less category, (2) The result of the cognitive ability of the learner after being taught by applying the discovery learning model with probing prompting technique was less category, (3) There was significant difference students achievement of result of cognitive ability after teached through application of discovery learning model with probing prompting technique.
\end{abstract}

Keywords: Implementation of discovery learning model, Probing prompting technique, Result of cognitive ability 


\section{PENDAHULUAN}

Sekolah merupakan tempat dimana manusia menimbah ilmu. Para orang tua mempercayakan anak-anaknya untuk menimbah ilmu di sekolah dengan tujuan peserta didik bisa menjadi manusia yang berkualitas. Guru menempati posisi utama untuk mewujudkan harapan orang tua peserta didik. Salah satu bentuk kualitas seseorang dapat dilihat dari kemampuan kognitif.

Salah satu upaya guru untuk dapat meningkatkan kemampuan kognitif peserta didik khususnya pada pembelajaran fisika adalah dengan merancang proses pembelajaran yang baik. Namun kenyataannya, beberapa guru belum dapat merancang pembelajaran dengan baik. Seringkali guru keasyikan sendiri selama menjelaskan di depan kelas tanpa membuat peserta didik mengerti dan langsung melakukan diskusi kelompok. Akibatnya, peserta didik menjadi kebingungan. Hal ini menjadi salah satu faktor penyebab rendahnya kemampuan kognitif peserta didik.

Ulasan di atas sesuai dengan hasil observasi peneliti. Dari hasil observasi awal berupa wawancara, diperoleh informasi bahwa hasil ulangan tengah semester (UTS) peserta didik tergolong sangat rendah. Di mana dari 24 peserta didik, $100 \%$ diantaranya memiliki nilai kognitif di bawah nilai Kriteria Ketuntasan Minimal (KKM) dengan nilai KKM adalah 68 .

Pada observasi berikutnya, dilakukan pembagian lembar kuesioner berupa pertanyaanpertanyaan terkait keluhan pembelajaran fisika di kelasX MIPA 2. Ditemukan, banyak peserta didik yang mengatakan bahwa fisika itu susah, rumit serta mengeluhkan proses pembelajaran fisika yang kurang efektif. Di mana, seringkali peserta didik kekurangan perhatian dari guru dan saat guru menjelaskan, guru keasyikan sendiri tanpa membuat peserta didik mengerti. Dari pemaparan di atas dapat disimpulkan bahwa proses pembelajaran di kelas X MIPA 2 masih kurang terstruktur.

Untuk mengatasi kesulitan-kesulitan tersebut, salah satu solusi yang dapat dilakukan adalah dengan menciptakan proses pembelajaran yang dapat meningkatkan kemampuan kognitif peserta didik.Salah satu solusi alternatif tersebut adalah model discovery learning. Di sisi lain, salah satu kendala dalam pembelajaran discovery learning adalahpeserta didik yang lamban dalam berpikir, akan cenderung bingung sedangkan peserta didik yang lebihpandai akan memonopoli proses pembelajaran di kelas [9]. Untuk meminimalisir keadaan tersebut dibutuhkan sebuah teknik pembelajaran yang dapat merangsang kreativitas peserta didik dan membantu peserta didik dalam menemukan pengetahuan baru. Menurut Megariati teknik probing prompting cukup efektif dalam upaya meningkatkan hasil belajar dan aktivitas peserta didik [9]. Sehingga diyakini bahwa teknik probing prompting ini mendukung dalam proses pembelajaran menggunakan model discovery learning dalam meningkatkan kemampuan kognitif peserta didik.

Penelitian pendukung yang berjudul model discovery learning disertai teknik probing prompting dalam pembelajaran fisika di MA [9]. Dengan hasil kognitif kelas eksperimen $(74,03)$ lebih baik dari kelas kontrol $(66,52)$. Penelitian serupa dilakukan mengenai penerapan teknik pembelajaran probing prompting untuk meningkatkan hasil belajar fisika pada siswa kelas VIII A SMP Negeri 1 Banawa Tengah [10]. Dari hasil penelitian tersebut menyimpulkan bahwa hasil belajar pada siklus -1 sebesar $65,83 \%$ dan pada pelaksanaan tindakan siklus -2 meningkat menjadi $81,83 \%$.

\section{Discovery Learning}

Pembelajaran discovery merupakan nama lain dari pembelajaran penemuan. Sesuai dengan namanya, model ini mengarahkan peserta didik untuk dapat menemukan sesuatu melalui proses pembelajaran yangdilakoninya [8].

\section{Stimulation \\ Rangsangan)}

Pertama-tama pada tahap ini, pelajar dihadapkan pada sesuatu yang menimbulkan kebingungannya, agar timbul keinginan untuk menyelidiki sendiri. Di samping itu guru dapat memulai kegiatan PBM dengan mengajukan pertanyaan, anjuran membaca buku, dan aktivitas belajar lainnya yang mengarah pada persiapan pemecahan masalah. Stimulasi pada tahap ini berfungsi untuk menyediakan kondisi interaksi belajar yang dapat mengembangkan dan membantu peserta didik dalam mengeksplorasi bahan. Dalam hal ini, Bruner memberikan stimulation dengan menggunakan teknik bertanya yaitu dengan mengajukan pertanyaan-pertanyaan yang dapat menghadapkan peserta didik pada kondisi internal yang mendorong eksplorasi. 


\section{Problem Statement \\ (Pernyataan/Identifikasi Masalah)}

Setelah dilakukan stimulation, guru memberi kesempatan kepada peserta didik untuk mengidentifikasi sebanyak mungkin masalah yang relevan dengan bahan pelajaran, kemudian salah satunya dipilih dan dirumuskan dalam bentuk hipotesis (jawaban sementara atas pertanyaan masalah)

\section{Data Collection (Pengumpulan Data)}

Pada saat peserta didik melakukan eksperimen atau eksplorasi, guru memberi kesempatan kepada para peserta didik untuk mengumpulkan informasi sebanyak-banyaknya yang relevan untuk membuktikan benar atau tidaknya hipotesis. Data dapat diperoleh melalui membaca literatur, mengamati objek, wawancara dengan narasumber, melakukan uji coba sendiri dan sebagainya.

\section{Data Processing (Pengolahan Data)}

Data processing disebut juga dengan pengkodean (coding) kategorisasi yang berfungsi sebagai pembentukan konsep dan generalisasi. Dari generalisasi tersebut peserta didik akan mendapatkan pengetahuan baru tentang alternatif jawaban yang perlu mendapat pembuktian secara logis.

\section{Verification (pembuktian)}

Pada tahap ini peserta didik melakukan pemeriksaan secara cermat untuk membuktikan benar atau tidaknya hipotesis yang telah ditetapkan, dihubungkan dengan hasil data processing. Berdasarkan hasil pengolahan dan tafsiran, atau informasi yang ada, pernyataan atau hipotesis yang telah dirumuskan terdahulu itu kemudian dicek, apakah terjawab atau tidak, apakah terbukti atau tidak.

\section{Generalization}

(Menarik Kesimpulan/Generalisasi)

Tahap generalisasi atau menarik kesimpulan adalah proses menarik sebuah kesimpulan yang dapat dijadikan prinsip umum dan berlaku untuk semua kejadian atau masalah yang sama dengan memperhatikan hasil verifikasi. Berdasarkan hasil verifikasi, maka dirumuskan prinsip-prinsip yang mendasari generalisasi.

\section{Teknik Probing Prompting}

Probing prompting menurut arti katanya, probing adalah penyelidikan, pemeriksaan dan prompting adalah mendorong atau menuntun.
Penyelidikan atau pemeriksaan di sini bertujuan untuk memperoleh sejumlah informasi yang telah ada pada peserta didik agar dapat digunakan untuk memahami pengetahuan atau konsep baru [1].

\section{Ranah Kognitif}

Ranah kognitif menurut Ali dan Khaeruddin, ranah kognitif adalah mengenai kemampuan intelektual peserta didik seperti yang ditampakkan dalam menyelesaikan soal-soal fisika, menyusun suatu karangan, atau dalam menyelesaikan berbagai jenis soal yang membutuhkan "pemikiran" [2]. Hasil belajar intelektual terdiri atas enam yang disempurnakan oleh lorin Anderson Krathwohl dengan istilah serta urutan sebagai berikut: remembering (mengingat), understanding (memahami), applying (diterapkan), analyzing (menganalisis), evaluating (menilai), dan creating (mencipta) [8].

\section{METODE}

\section{Jenis Penelitian}

Jenis penelitian yang digunakan dalam penelitian ini adalah penelitian pre-eksperimental yang menggunakan desain One-Group PretestPosttest sebagai berikut [13]:

$$
\begin{array}{lll}
\mathbf{O}_{1} & \mathbf{X} & \mathbf{O}_{2}
\end{array}
$$

Keterangan:

$\mathrm{O}_{1}$ : Pengukuran (sebelum diberi perlakuan/pretest)

$\mathrm{X}$ : Perlakuan (model discovery learning denganteknik probing prompting)

O2 :Pengukuran (sesudah diberi perlakuan/posttest)

\section{Populasi Penelitian}

Populasi dalam penelitian ini adalah seluruh peserta didik kelas XI MIPA SMA Negeri 1 Pamboang tahun ajaran 2017/2018 yang berjumlah 75 orang.

\section{Validasi Instrumen}

Instrumen tes kemampuan kognitif yang digunakan dalam penelitian ini, terlebih dahulu dinilai oleh dua orang ahli dan hasil penilaian dari kedua ahli tersebut kemudian dianalisis dengan menggunakan validitas isi secara keseluruhan yang dikemukakan oleh Gregory. Koefisien validitas isi tersebut dihitung dengan menggunakan rumus Gregory sebagai berikut [11]:

Validasi Isi $=\frac{D}{(A+B+C+D)}$ 
Keterangan:

A : Rater 1 memberikan skor lemah, rater 2 memberikan skor lemah.

B : Rater 1 memberikan skor kuat, rater 2 memberikan skor lemah.

C: Rater 1 memberikan skor lemah, rater 2 memberikan skor lemah.

D : Rater 1 memberikan skor kuat, rater 2 memberikan skor kuat.

Berdasarkan ketentuan dari kesepakatan antar ahli untuk validasi isi bahwa item dengan status D dapat langsung digunakan, untuk item dengan statusC dan B akan dikoreksi lagi sebelum digunakan, sedangkan untuk item dengan status $\mathrm{A}$ akan langsung dibuang [5]. Adapun kategori validitas isi dapat dilihat pada tabel 1 berikut:

Tabel 1. Kategori Valid Isi

\begin{tabular}{cc}
\hline Interval & Kategori \\
\hline$>0,8$ & Tinggi \\
$0,4-0,8$ & Sedang \\
$<0,4$ & Rendah \\
\hline
\end{tabular}

\section{Teknik Analisis Data}

\section{Teknik Analisis Deskriptif}

Skor Rata-Rata ( $\overline{\mathrm{x}})[2]$

$\overline{\mathrm{x}}=\frac{\sum \mathrm{f}_{\mathrm{i}} \mathrm{X}_{\mathrm{i}}}{\sum \mathrm{f}_{\mathrm{i}}}$

Standar Deviasi [14]

$S_{d}=\sqrt{\frac{\sum f_{i}\left(X_{i}-\bar{X}\right)^{2}}{n-1}}$

\section{Perolehan nilai:}

Untuk mengetahui nilai yang diperoleh peserta didik, maka skor dikonversi ke nilai dengan menggunakan rumus [7]:

Nilai $=\frac{\text { Skor Peserta Didik }}{\text { Skor Maksimum }} \times 100$

Kategori hasil belajar ditunjukkan pada tabel 2.

Tabel 2. Kategori Penilaian Aspek Kognitif

\begin{tabular}{cc}
\hline Kategori & Nilai \\
\hline Sangat Baik (SB) & $80 \leq \mathrm{SB} \leq 100$ \\
Baik (B) & $70 \leq \mathrm{B} \leq 79$ \\
Cukup (C) & $60 \leq \mathrm{C} \leq 69$ \\
Kurang (K) & $<60$ \\
\hline
\end{tabular}

Keterlaksanaan Penerapan Model Pembelajaran
Nilai keterlaksanaan penerapan model pembelajaran dapat ditentukan dengan menggunakan rumus sebagai berikut [6]:

Nilai $=\frac{\sum \text { penilaian tiap aspek }}{\sum \text { aspek }}$

Tabel 3. Skala Penilaian Keterlaksanaan Penerapan Model Pembelajaran

\begin{tabular}{cc}
\hline Nilai & Kriteria \\
\hline 5 & Sangat Baik \\
4 & Baik \\
3 & Cukup Baik \\
2 & Kurang Baik \\
1 & Tidak Baik \\
\hline
\end{tabular}

\section{Teknik Analisis Inferensial}

Analisis statistik inferensial digunakan untuk menguji hipotesis penelitian. Sebelum dilakukan pengujian hipotesis terlebih dahulu dilakukan uji prasyarat yaitu uji normalitas.

\section{Uji Normalitas}

Pengujian normalitas dalam penelitian ini menggunakan rumus Chi-Kuadrat sebagai berikut [14]:

$X^{2}=\sum_{i=1}^{k} \frac{\left(f_{0}-f_{e}\right)^{2}}{f_{2}}$

Kriteria pengujian: Data berdistribusi normal bila $\mathrm{X}_{\text {hitung lebih kecil dari } \mathrm{X}_{\text {tabel }}^{2} \text { dimana }}$ daftar $\mathrm{X}^{2}$ dengan $\mathrm{dk}=(\mathrm{k}-1)$ pada taraf signifikan $\alpha$ $=0,05$.

\section{Uji Hipotesis}

Pengujian hipotesis pada penelitian ini menggunakan uji-t, dengan $\alpha=0,05$ [3] yaitu:

$\mathrm{t}=\frac{\mathrm{Md}}{\sqrt{\frac{\sum \mathrm{xd}^{2}}{\mathrm{~N}(\mathrm{~N}-1)}}}$

Kriteria pengujian untuk uji $\mathrm{t}$ adalah sebagai berikut [12]:

$t_{\text {hitung }} \leq t_{\text {tabel }}$ maka $\mathrm{H}_{0}$ diterima

$t_{\text {hitung }}>t_{\text {tabel }}$ maka $\mathrm{H}_{\mathrm{a}}$ diterima

Uji hipotesis dilakukan untuk menjawabhipotesis penelitian. Hipotesis pada penelitian ini sebagai berikut:

$\mathrm{H}_{\mathrm{o}}$ : Tidak terdapat perbedaan signifikan antara kemampuan kognitif peserta didik kelas XI MIPA SMA Negeri 1 Pamboang sebelum dan 
setelah diterapkan model pembelajaran discovery learning dengan teknik probing prompting.

$\mathrm{H}_{\mathrm{a}}$ : Terdapat perbedaan signifikan antara kemampuan kognitif peserta didik kelas XI MIPA SMA Negeri 1 Pamboang sebelum dan setelah diterapkan model pembelajaran discovery learning dengan teknik probing prompting.

Adapun rumusan hipotesis yaitu sebagai berikut [15]:

$$
\begin{aligned}
& H_{0}: \mu_{1}=\mu_{2} \\
& H_{a}: \mu_{1} \neq \mu_{2}
\end{aligned}
$$

$\mu_{1}$ : Skor rata-rata hasil kemampuan kognitif peserta didik kelas XI MIPA SMA Negeri 1 Pamboang sebelum diterapkan model pembelajaran discovery learning dengan teknik probing prompting.

$\mu_{2}$ : Skor rata-rata hasil kemampuan kognitif peserta peserta didik kelas XI MIPA SMA Negeri 1 Pamboang setelah diterapkan model pembelajaran discovery learning dengan teknik probing prompting.

\section{HASIL DAN DISKUSI}

\section{Hasil Analisis Deskriptif}

Berdasarkan hasil analisis diperoleh skor rata-rata pretest 4,7 dan posttest 10,6 . Jika skor ini dikonversi ke bentuk nilai diperoleh nilai pretest 23,5 dan posttest 53,0 yang keduanya digolongkan dalam kategori kurang. Dilihat dari skor yang diperoleh peserta didik dapat dikatakan bahwa ada peningkatan skor walaupun masih dalam kategori yang sama. Akan tetapi jika dianalisis menggunakan uji $\mathrm{N}-$ Gain nilai gsebesar 0,37 yang berarti berada pada kategori sedang.

Keterlaksanaan model pembelajaran tersebut dinilai oleh seorang observer yang telah ditetapkan, kemudian diolah. Adapun nilai yang diperoleh keterlaksanaan penerapan model pembelajaran sebagai berikut:

Tabel 4. Keterlaksanaan Model Pembelajaran

\begin{tabular}{ccc}
\hline Pertemuan & Nilai & Kriteria \\
\hline 1 (Pretest) & - & - \\
2 & 5 & Sangat Baik \\
3 & 5 & Sangat Baik \\
4 & 5 & Sangat Baik \\
5 & 4 & Baik \\
6 (Posttest) & - & - \\
\hline
\end{tabular}

Berdasarkan hasil pretest dan posttest ditinjau dari indikator untuk ranah kognitif $\mathrm{C} 1, \mathrm{C} 2$, C3, dan C4 dilihat sebagai berikut:
Tabel 5. Perbedaan Hasil Pretest dan Posttest

\begin{tabular}{ccccc}
\hline \multirow{2}{*}{ Pengukuran } & \multicolumn{4}{c}{ Ranah Kognitif } \\
\cline { 2 - 5 } & C1 & C2 & C3 & C4 \\
\hline $\begin{array}{c}\text { Pretest } \\
\text { Posttest }\end{array}$ & 2,00 & 6,20 & 5,67 & 3,43 \\
\hline
\end{tabular}

Berdasarkan tabel 5 perbedaan jumlah hasil pretest dan posttest ditinjau dari indikator ranah kognitif, terlihat dari 4 indikator untuk ranah kognitif semuanya mengalami peningkatan. Peningkatan kemampuan kognitif paling tinggi terdapat padaindikator $\mathrm{C} 1$ dari 2 menjadi 18,5 dan peningkatan indikator paling sedikit terdapat pada indikator $\mathrm{C} 4$ dari 3,43 menjadi 7, 43. Hal ini berarti indikator $\mathrm{C} 1, \mathrm{C} 2, \mathrm{C} 3$, dan $\mathrm{C} 4$ mengalami peningkatan setelah menerapkan model discovery learning dengan teknik probing prompting.

\section{Hasil Analisis Inferensial Uji Normalitas}

Hasil pengujian normalitas data skor kemampuan kognitif peserta didik sebelum dan setelah diterapkan model pembelajaran discovery learning dengan teknik probing prompting masingmasing $X_{\text {hitung }}^{2}=3,7978<X_{\text {tabel }}^{2}=9,488$ dan $X_{\text {hitung }}^{2}=3,343<X_{\text {tabel }}^{2}=9,488$ yang berarti semuanya berdistribusi normal dengan $d k=(\mathrm{k}-1)$ pada taraf signifikan $\alpha=0,05$.

\section{Uji Hipotesis}

Pengujian hipotesis yang telah dianalisis menggunakan uji-t dengan taraf ketidakpastian 5\% dan $\mathrm{dk}=4$, diperoleh harga $\mathrm{t}_{\text {hitung }}=7,692>\mathrm{t}_{\text {tabel }}=$ 2,093 , yang berarti terdapat perbedaan signifikan antara kemampuan kognitif peserta didik kelas XI MIPA SMA Negeri 1 Pamboang sebelum dan setelah diterapkan model pembelajaran discovery learning dengan teknik probing prompting.

\section{SIMPULAN DAN SARAN Simpulan}

Hasil kemampuan kognitif peserta didik kelas XI MIPA SMA Negeri 1 Pamboang sebelum diterapkan model discovery learning dengan teknik probing prompting dalam kategori kurang. Hasil kemampuan kognitif peserta didik kelas XI MIPA SMA Negeri 1 Pamboang setelah diterapkan model discovery learning dengan teknik probing prompting dalam kategori kurang. Terdapat perbedaan signifikan antara hasil kemampuan kognitif peserta didik kelas XI MIPASMA Negeri 
1 Pamboang sebelum dan setelah diterapkan model discovery learning dengan teknik probing prompting.

\section{Saran}

Keterlaksanaan pembelajaran menggunakan model discovery learning dengan teknik probing prompting akan lebih baik jika tidak bertepatan dengan persiapan perayaan HUT RI. Akan lebih baik jika jam pelajaran fisika tidak terlalu awal agar peserta didik tidak lagi datang terlambat. Serta jika hendak menggunakan LCD projector, usahakan agar LCD projector tersebut disediakan kurang lebih 10 menit sebelum jam pelajaran dimulai. Menyadarkan peserta didik bahwa betapa pentingnya menghargai waktu, sehingga peserta didik dapat memanfaatkan jam pelajaran dengan baik. Model discovery learning dan teknik probing prompting sesuai untuk jumlah peserta didik yang sedikit.

\section{DAFTAR PUSTAKA}

[1] Afifah Yuli. 2014. Pengaruh Teknik Pembelajaran Probing Prompting Terhadap Pemahaman Konsep Dan Keterampilan Berpikir Siswa Kelas VIII MTs-N Jambewangi Selopuro Blitar. Skripsi. Institut Agama Islam NegeriTulunggun

[2] Ali, Sidin dan Khaeruddin. 2021. Evaluasi Pembelajaran. Makassar: Badan Penerbit UNM.

[3] Arikunto, Suharsimi. 2014. Prosedur PenelitianSuatu Pendekatan Praktik. Jakarta: Bumi Aksara

[4] Arsyad, Arie Arma. 2015. Pengembangan Perangkat Pembelajaran Berorientasikan Model Cooperative Problem Solving Pada Pokok Bahasan Optik Untuk Meningkatkan Hasil Belajar Siswa SMP (Tesis Tidak Dipublikasikan). Surabaya: Universitas Negeri Surabaya

[5] Humairah, Nur Aisyah. 2010. Implementasi Kurikulum Tingkat Satuan Pendidikan Dalam Pembelajaran Fisika Pada SMP Negeri Di Kabupaten Polewali Mandar. Tesis: UniversitasNegeri Makassar

[6] Ibrahim, M. 2005. Asesmen Berkelanjutan. Surabaya: Unipress Unesa

[7] Kemendikbud. 2014. Materi pelatihan implementasi kurikulum 2013 tahun 2014 mata pelajaran SMA/SMK.Jakarta: Badan
Pengembangan Sumber Daya Manusia Pendidikan dan Kebudayaan dan Penjaminan Mutu Pendidikan Kementrian Pendidikan dan Kebudayaan

[8] Kosasih, E. 2014. Strategi Belajar dan Pembelajaran implementasi kurikulum 2013.Bandung:Yrama Widya

[9] Kusuma, Tiani Alfi, dkk. 2015. Model Pembelajaran Discovery Learning Disertai Teknik Probing Prompting Dalam Pembelajaran Fisika Di MA. Jurnal pendidikan Fisika Vol. 3:336-341

[10] Mutmainnah, Sitti, dkk. 2013. Penerapan Teknik Pembelajaran Probing -Prompting Untuk Meningkatkan Hasil Belajar Fisika pada Siswa Kelas VIII A SMP Negeri I Banawa Tengah. Jurnal Pendidikan Fisika Tadulako (JPFT) vol. 2:38-43

[11] Retnawati, Heri. 2016. Analisis Kuantitatif Instrumen Penelitian. Yogyakarta: Parama Publishing.

[12] Siregar, Syofian. 2014. Statistika Deskriptif Untuk Penelitian. Jakarta: Rajawali Pers.

[13] Sugiyono. 2015. Metode Penelitian Pendidikan. Bandung: Alfabeta

[14] _. 2005. Statistika Untuk Penelitian. Bandung: Alfabeta

[15] Susetyo, Budi. 2017. Statistika untuk Analisis Data Penelitian. Bandung: Refika Aditama. 